\title{
Frequency and clinico-topographic distribution patterns of pruritic papular eruption in HIV patients in a Nigerian Tertiary Hospital
}

\author{
Obioma Ekpe ${ }^{1}$, Gerald Dafe Forae², Benson Okwara ${ }^{3}$, Chimezie Godswill Okwuonu', \\ Roli Cynthia Madubuko ${ }^{3}$
}

${ }^{1}$ Department of Medicine, Federal Medical Centre Umuahia, Abia State, Nigeria, ${ }^{2}$ Department of Pathology, University of Benin Teaching Hospital, Benin City, Nigeria, ${ }^{3}$ Department of Medicine, University of Benin Teaching Hospital, Benin City, Nigeria

Corresponding author: Dr. Obioma Ekpe, E-mail: uncleprinceo@gmail.com

\begin{abstract}
Background: Pruritic papular eruption of HIV (PPE-HIV) has been well described in some sub-Saharan Africa countries and elsewhere, with varying geographical prevalence. Aims: To determine the frequency and the clinico-topographic distribution of these lesions as seen in the University of Benin Teaching Hospital, Benin-City, Nigeria and to compare our findings with those seen in other parts of the world. Materials and Methods: This study was carried out at the University of Benin Teaching Hospital (UBTH), Benin-City. University of Benin Teaching Hospital is an 800-bed Federal Government tertiary hospital which offers both in-patient and out-patient services. Specimen collection and analysis of the study lasted 18 months (January, 2015 to June, 2016). All HIV patients at presentation in clinic and wards with suspicion of PPE during the study period were interviewed examined. Qualitative variables were described in percentages and proportions. Continuous variables were summarized as mean and standard deviation when normally distributed. Results: A total of 106 patients were studied, there were 41 (38.7\%) males and $65(61.3 \%)$ females with a male to female ratio of 1:1.6. Their mean age was $40.2 \pm 10.4$ years. Majority $(79.3 \%)$ of patients had at least secondary education and males were slightly better educated than females. Most (33.0\%) of the subjects were traders, the mean duration of diagnosis of PPE was $5.22 \pm 3.92$ and $6.05 \pm 5.21$ months for males and females respectively, while the overall mean duration of diagnosis of PPE was $5.73 \pm 4.75$ months. The most commonly reported sites initially affected by PPE among the patients were lower limb (51.0\%) and upper limb (39.6\%). Conclusion: Majority of lesions of Pruritic papular eruptions (PPE) of HIV in this study were found in educated females. The mean age of distribution of PPE was found in the $4^{\text {th }}$ decades. Furthermore PPE is distributed predominantly on the exposed parts of the body especially the upper and lower limbs.
\end{abstract}

Key words: Human Immmuno-deficency Virus; Pruritic papular eruption; clinic-topographic

\section{INTRODUCTION}

Pruritic papular eruption of human immunodeficiency virus (PPE-HIV) is one of the most common dermatologic disorders in untreated HIV-infected adults. Pruritic papular eruption of HIV (PPE-HIV) has been well described in some sub-Saharan Africa countries and elsewhere, with varying geographical prevalence. ${ }^{1}$ Report of PPE emerged early in the course of the HIV epidemic as far back in 1983 in series of studies conducted in Democratic Republic of Congo [1], Mali [2], Nigeria [3], Tanzania [4], Togo [5], Zambia [6], and other Africa countries, where it was described as an extremely pruritic diffuse skin eruption occurring in HIV infected patient.

Studies have it that between $11 \%$ and $46 \%$ of HIV positive patients are affected with PPE, depending on the geographical location $[7,8]$. In Haiti it accounted for 46\% [7], Thailand (33-37\%) [8], in Zaire among

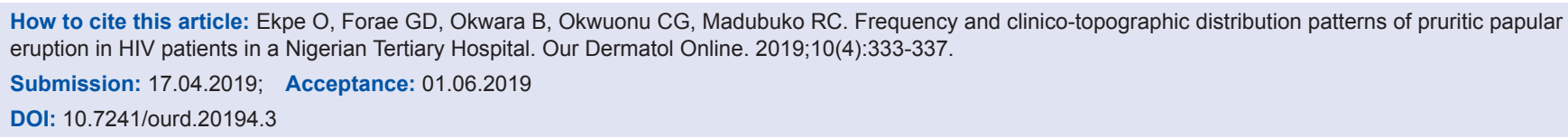


hospitalized patients (18\%) [9], Kenya (5\%) [10], and $(16.7 \%)$ in Nigeria [11].

There are few reported cases of pruritic papular eruption of HIV in United States of America (USA), except in areas with high mosquito prevalence such as Southern Florida [12], where a PPE prevalence of $11 \%$ was reported by Goldstein et al [13].

Only few studies on Pruritic papular eruption of HIV have been done in Nigeria and as such there is the need to study PPE cases as they present to the University of Benin Teaching Hospital.

The main objective of this study is to determine the frequency and the clinic-topographic distribution of these lesions as seen in the University of Benin Teaching Hospital, Benin-City, Nigeria and to compare our findings with those seen in other parts of the world.

\section{MATERIALS AND METHODS}

\section{Study Area}

This study was carried out at the University of Benin Teaching Hospital (UBTH) Benin-City. UBTH is an 800-bed Federal Government tertiary hospital which offers both in-patient and out-patient services. It is located in Egor Local Government Area of Edo State, Nigeria. It receives referrals from Edo state and neighbouring States like Delta, Ondo, Anambra, Ekiti, Kogi, and Bayelsa.

\section{Study Duration, Design and Population}

Specimen collection and analysis of the study lasted 18 months (January, 2015 to June, 2016) after approval by the ethical committee. The study design was a crosssectional descriptive study of confirmed HIV-infected patients with clinically active PPE lesions presenting at the Dermatology outpatient clinic, the HIV/ART clinic of the Dermatology and Infectious disease unit of Internal Medicine department of UBTH and those admitted as in-patients in the medical wards of the UBTH.

\section{Sampling Method}

All HIV patients at presentation in clinic and wards with suspicion of PPE during the study period were interviewed examined and skin biopsy sample taken and patients with histological evidence of PPE were consecutively recruited into the study until the required sample size was attained.

\section{Data Analysis}

Data generated from the study was entered into and analyzed using the Statistical Package of Social Science (SPSS) version 21. Qualitative variables were described in percentages and proportions. Continuous variables were summarized as mean and standard deviation when normally distributed. Non-normally distributed quantitative variables were summarized as median. The findings were presented in appropriate tables.

\section{RESULTS}

\section{Social Demographic Characteristics of the Patients}

A total of 106 patients were studied and their findings presented below. There were $41(38.7 \%)$ males and $65(61.3 \%)$ females with a male to female ratio of $1: 1.6$. Their mean age was $40.2 \pm 10.4$ years. The males (mean $=40.9 \pm 8.8$ years) were slightly older than females (mean $=39.7 \pm 11.4$ years). Majority $(79.3 \%)$ of patients had at least secondary education and males were slightly better educated than females. Thirty-eight (35.8\%) of patients were single, $48(45.3 \%)$ were married, $12(11.3 \%)$ were widowed and 4 respondents each $(3.8 \%)$ were divorced or separated. A higher proportion of males (48.8\%) than females $(43.1 \%)$ were married, while more females $(38.5 \%$; $13.9 \%)$ than males $(31.7 \% ; 7.3 \%)$ were single or widowed respectively. Most $(33.0 \%)$ of the subjects were traders, while house-wives constituted the least $(5.7 \%$ ) based on occupational status - Table 1 .

\section{Duration of Diagnosis of PPE by Gender}

Table 2 show the mean duration of diagnosis of PPE was $5.22 \pm 3.92$ and $6.05 \pm 5.21$ months for males and females respectively, while the overall mean duration of diagnosis of PPE was $5.73 \pm 4.75$ months. A higher proportion of male subjects were diagnosed earlier ( $\leq 6$ months) than the female, however there was no significant difference between the sexes by duration of diagnosis.

\section{Initial (First) Part of the Body Affected by PPE Lesions according to Gender}

The most commonly reported sites initially affected by PPE among the patients were lower limb $(51.0 \%)$ and upper limb (39.6\%), while the face is the least affected 
initially among all the patients, and there was also no significant difference in the site first affected by gender as shown in Table 3.

\section{Distribution of Patients with PPE according to BMI Class}

Forty-four (41.5\%) of the patients were underweight, $55(51.9 \%)$ had normal weight and 7 (6.6\%) of the participants were overweight as shown in Table 4:12. Overall mean BMI of all the patients was $19.2 \pm 3.5 \mathrm{~kg} / \mathrm{m}^{2}$. Mean BMI of the females $-19.8 \pm 3.8 \mathrm{~kg} / \mathrm{m}^{2}$ was slightly higher than the mean BMI of the male $-18.3 \pm 2.8 \mathrm{~kg} / \mathrm{m}^{2}$. (Table 4)

\section{DISCUSSIONS}

In this study majority of patients with pruritic papular eruption of HIV were women (61.3\%). This was similar to the findings by Mawenzi et al [10] in Kenya where $70 \%$ of his study population were females. A similar observation was made by Resneck et al [14] who reported that $81 \%$ of PPE patients were females. Other studies in Kenya ${ }^{10}$ also reported that $70 \%$ of patients with PPE were female. These were in contrast to a study from the Democratic Republic of Congo by Colebunder et al who stated that the frequency of PPE seen in male and female were approximately equal [9]. The reason for the disparity is unknown. Perhaps the greater susceptibility of female to HIV infection may explain the gender differences in HIV prevalence [15]. It may also mean that women are more skin health and cosmetically conscious and do seek treatment better than men as observed in Cameroon by Josephine et al [16]. and in Benin city, Edo state by Omuemu et al [17].

The mean age of the participants in this study was $40.2 \pm 10.4$ years. This was comparable to a study done in Uganda where the mean age of participants was noted to be $35 \pm 8$ years [18]. A study in India reported that the mean age of the PPE patients was $34.2 \pm 7.5$ years [19]. Most of the patients with PPE in this study (68.8\%) were less than 45 years old, in keeping with the age group more likely to be HIV infected as reported in similar studies in our environment $[20,21]$.

Majority of patients (79.3\%) in this study had at least secondary education and above. This was in keeping with a previous study by Egube et al in Benin City that corroborated to high literacy level among the inhabitants of Benin City and its environs [22].
Table 1: Socio-demographic Characteristics of the Patients by Gender

\begin{tabular}{lccc} 
Characteristic & Male & Female & Total \\
& $\mathbf{n = 4 1 ( \% )}$ & $\mathbf{n = 6 5 ( \% )}$ & $\mathbf{n = 1 0 6 ( \% )}$ \\
\hline Age (in years) & $2(4.9)$ & $15(23.1)$ & $17(16.0)$ \\
$15-29$ & $26(63.4)$ & $30(46.2)$ & $56(52.8)$ \\
$30-44$ & $12(29.3)$ & $16(24.6)$ & $28(26.4)$ \\
$45-59$ & $1(2.4)$ & $4(6.2)$ & $5(4.7)$ \\
$\geq 60$ & $40.9 \pm 8.6$ & $39.7 \pm 11.4$ & $40.2 \pm 10.4$ \\
Mean \pm SD & & & \\
Level of Education & $6(14.6)$ & $4(6.2)$ & $10(9.4)$ \\
None & $4(9.8)$ & $8(12.3)$ & $12(11.3)$ \\
Primary & $17(41.5)$ & $28(43.1)$ & $45(42.5)$ \\
Secondary & $19(46.3)$ & $20(30.8)$ & $39(36.8)$ \\
Tertiary & & & \\
Religion & $37(90.2)$ & $58(89.2)$ & $95(89.6)$ \\
Christian & $4(9.8)$ & $7(10.8)$ & $11(11.4)$ \\
Islam & & & \\
Marital Status & $13(31.7)$ & $25(38.5)$ & $38(35.8)$ \\
Single & $20(48.8)$ & $28(43.1)$ & $48(45.3)$ \\
Married & $2(4.9)$ & $2(3.1)$ & $4(3.8)$ \\
Divorced & $3(7.3)$ & $9(13.9)$ & $12(11.3)$ \\
Widowed & $3(7.3)$ & $1(1.5)$ & $4(3.8)$ \\
Separated & & & \\
Occupation & $14(34.1)$ & $21(32.3)$ & $35(33.0)$ \\
Traders & $11(26.8)$ & $13(20.0)$ & $24(22.6)$ \\
Civil servants & $8(19.5)$ & $13(20.0)$ & $21(19.8)$ \\
Farmers/ & $8(19.5)$ & $12(18.5)$ & $20(18.9)$ \\
Artisans & $0(0.0)$ & $6(9.2)$ & $6(5.7)$ \\
Student & & & \\
House-wife & & & \\
\hline
\end{tabular}

Table 2: Duration of diagnosis of PPE by Gender

\begin{tabular}{lccc} 
Duration of diagnosis & Male & Female & Total \\
& $\mathbf{n = 4 1 ( \% )}$ & $\mathbf{n = 6 5 ( \% )}$ & $\mathbf{n = 1 0 6 ( \% )}$ \\
\hline$\leq 6$ months & $34(82.9)$ & $49(75.4)$ & $83(78.3)$ \\
$7-12$ months & $6(14.6)$ & $13(20.0)$ & $19(17.9)$ \\
$>12$ months & $1(2.4)$ & $3(4.6)$ & $4(3.8)$ \\
Mean \pm SD & $5.22 \pm 3.92$ & $6.05 \pm 5.21$ & $5.73 \pm 4.75$ \\
\hline
\end{tabular}

Table 3: Initial (first) part of the body affected by PPE according to Gender

\begin{tabular}{|c|c|c|c|}
\hline Part of the Body & $\begin{array}{c}\text { Male } \\
\mathrm{n}=41(\%)\end{array}$ & $\begin{array}{c}\text { Female } \\
\mathrm{n}=65(\%)\end{array}$ & $\begin{array}{c}\text { Total } \\
\mathrm{n}=106(\%)\end{array}$ \\
\hline Lower Limb & $21(51.2)$ & $33(50.8)$ & $54(51.0)$ \\
\hline Upper Limb & $16(39.0)$ & $26(40.0)$ & $42(39.6)$ \\
\hline Face & $4(9.8)$ & $6(9.2)$ & $10(9.4)$ \\
\hline
\end{tabular}

Table 4: Distribution of Patients with PPE according to BMI Class

\begin{tabular}{cccc}
\hline BMI $\left(\mathbf{k g} / \mathbf{m}^{2}\right)$ & $\begin{array}{c}\text { Male } \\
\mathrm{n}=\mathbf{4 1}(\%)\end{array}$ & $\begin{array}{c}\text { Female } \\
\mathrm{n}=65(\%)\end{array}$ & $\begin{array}{c}\text { Total } \\
\mathrm{n}=106(\%)\end{array}$ \\
\hline $\begin{array}{c}\text { Underweight } \\
(<18.5)\end{array}$ & $21(51.2)$ & $23(35.4)$ & $44(41.5)$ \\
$\begin{array}{c}\text { Normal Weight } \\
(18.5-24.9)\end{array}$ & $20(48.8)$ & $35(53.8)$ & $55(51.9)$ \\
$\begin{array}{c}\text { Overweight } \\
(25-29.9)\end{array}$ & $0(0.0)$ & $7(10.8)$ & $7(6.6)$ \\
Mean \pm SD & $18.3 \pm 2.8$ & $19.8 \pm 3.8$ & $19.2 \pm 3.5$ \\
\hline
\end{tabular}


The mean duration of PPE skin lesion as reported by participants before diagnosis was $5.73 \pm 4.75$ months. This was comparable to the findings of Lakshmi et al [23] in India who reported mean PPE duration of 6.5 months at diagnosis. A study done in Uganda found out that majority (58\%) of PPE patients had PPE for more than 6 months at diagnosis [24]. The time lag before patient presentation to the clinic and the intense pruritus could have been responsible for the secondary changes noticed in patients with this skin lesion.

In addition to its presence in large number of patient, PPE is often one of the early cutaneous manifestations of HIV. In a study done in Kenya by Mawenzi et al [10] on the epidemiology and clinical spectrum of cutaneous disease manifesting among newly diagnosed HIV seropositive adult in Kenya; it was reported that out of 394 cases 20 patients accounting for 5\% had PPE. PPE is often one of the early cutaneous manifestations of HIV. Liautaud et al [25], in a study of PPE-HIV in Haitian patients, observed pruritic papular skin lesion as the initial symptom in $70 \%$ of patients and similar findings were described in Democratic Republic of Congo, by Colebunder et al [9], where $51 \%$ reported that the skin eruption was their initial manifestation of HIV.

Pruritic papular eruptions (PPE) are characterized by chronic pruritus and symmetric papular eruptions on the trunk and extremities, with absence of other definable causes of itching in an HIV-infected patient $[15,26]$. The face may be involved in some patients and the condition tends to wax and wane [16,23].

The review of body parts affected by the rash in this study showed that majority $(98.1 \%)$ of the patients with Pruritic papular eruptions of HIV have the lesions on their extremities as shown in Figs 1 and 2. Other investigators have reported that the lesions of PPE were mostly located on the extremities [11,25,27].

The nutritional status of PPE patients were assessed using body mass index (BMI). It was noted in the study centre, that $41.5 \%$ of the study population were under-weight while $51.9 \%$ had normal weight. The reason for the under nutrition recorded in $41.5 \%$ of patients in this study could be due to advanced immunosuppression which could be associated with opportunistic infection. More so, it is documented that disease progression and viral load increments in HIV patients lead to overproduction of cytokines such as TNF that culminates in weight loss [28].

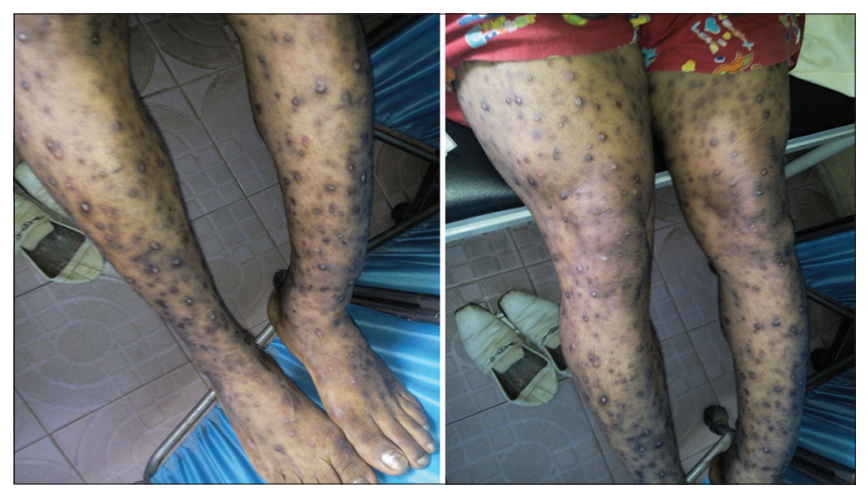

Figure 1: Lab Patient with Pruritic papular eruption of HIV affecting the lower limb.

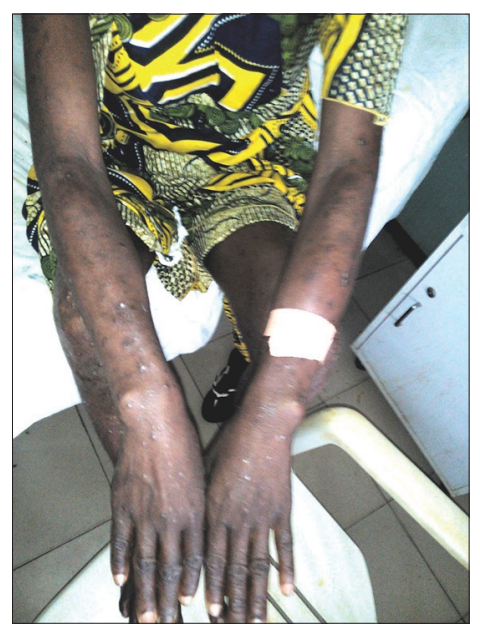

Figure 2: Patient with Pruritic papular eruption -HIV affecting the upper limb.

\section{CONCLUSION}

In conclusion majority of lesions of Pruritic papular eruptions (PPE) of HIV in this study were found in females and were educated. The mean age of distribution of PPE was found in the $4^{\text {th }}$ decades. Furthermore PPE is distributed predominantly on the exposed parts of the body especially the upper and lower limbs.

\section{Statement of Human and Animal Rights}

All procedures followed were in accordance with the ethical standards of the responsible committee on human experimentation (institutional and national) and with the Helsinki Declaration of 1975, as revised in 2008 .

\section{Statement of Informed Consent}

Informed consent was obtained from all patients for being included in the study. 


\section{REFERENCES}

1. Bason MM, Berger TG, Nesbitt LT Jr. Pruritic papular eruption of HIV-disease. Int J Dermatol. 1993;32:784-9.

2. Mahe A, Simon F, Coulibaly S. Predictive value of seborrheic dermatitis and other common dermatosis for HIV infection in Bamako, Mali. J Am Acad Dermatol. 1996;34:1084-6.

3. Olumide YM, Dada AJ, Sogbanmu IB, Ariuna GA. Seroprevalence study of HIV-1, HIV-II and HTLV-I among patients at the Dermato-venerology clinic of the Lagos University Teaching Hospital. Int J Dermatol. 1997;36:741-4.

4. Pallangyo KJ. Cutaneous findings associated with HIV disease including AIDS: experience from sub Saharan African. Trop Doct. 1992;22:35-41.

5. Pitche P, Tchangai- wallak, Napo-Koura G. Prevalence of skin manifestations in AIDS patient in the Lome-Tokoin University Hospital (Togo). Sante. 1995;5:349-52.

6. Hira SK, Wadhawan D, Kamanga J, Kavindel D, Macuacua R, Patil PS. et al. Cutaneous manifestations of human immunodeficiency virus in Lusaka, Zambia. J Am Acad Dermatol. 1988;19:451-7.

7. Liautaud B, Pape JW, DeHovitz JA, Thomas F, LaRoche AC, Verdier RI, et al. Pruritic skin lesions: A common initial presentation of acquired immunodeficiency syndrome. Arch Dermatol. 1989;125:629-32.

8. Sivayathorn A, Srihra B, Lasanguankul W. Prevalence of skin disease in patients infected with human immune deficiency virus Bangkok, Thailand: Ann Acad Med Singapore. 1995;24:528-33.

9. Colebunders R, Mann JM, Francis H, Bila K, Izaley L, Kakonde N, et al. Generalized pruritic papular eruption in African patients with HIV infection. AIDS. 1987;1:117-21.

10. Mawenzi LR, Oguttu RO, Williams CH, Joash A. Epidemiology and clinical spectrum of cutaneous diseases manifesting among newly diagnosed HIV seropositive adults in Nakuru County-kenya. Continental J Med Res. 2013;7:1-9.

11. Ukonu AB, Eze EU. Pattern of skin diseases at university of Benin Teaching Hospital, Benin City, Edo state, South-South Nigeria: a 12 month prospective study. Glob J Health Sci. 2012;4:148-57.

12. Hevia O, Jimenez-Acosta F, Ceballos PI, Gould EW, Pennys NS. Pruritic papular eruption of the acquired immunodeficiency syndrome: a clinicopathologic study. J Am Acad Dermatol. 1991;24:231-5.

13. Goldsteins B, Berman B, Sukenik E, Frankel SJ. Correlation of skin disorder with CD4 Lymphocyte count in patients with HIV/AIDS. J Am Acad Dermatol. 1997;36:262-4.

14. Resneck JS Jr, Van Beek M, Furmanski L, Oyugi J, LeBoit PE, Kambugu F, et al. Etiology of pruritic papular eruptions with HIV in Uganda. JAMA. 2004;292:2614-21.

15. Glynn JR, Corael M, Auvert B. Why do young women have a much higher prevalence of HIV than young men? A study in Kisumu Kenya and Ndola, Zambia. AID. 2001;15:551-60.
16. Josephine M, Issac E, George A, Ngole M, Albert SF. Pattern of skin manifestations and their relationship with CD4 counts among HIV/AIDS patients in Cameroon. Int. J Dermatol. 2006;45:280-4.

17. Omuemu VO, Okoje OH, Omuemu CE. Awareness of high blood pressure status, treatment and control in a rural community in Edo state. Niger J Clin Pract. 2007;10:2008-12.

18. Resneck JS Jr, Van Beek M, Furmanski L, Oyugi J, LeBoit PE, Kambugu F, et al. Etiology of pruritic papular eruptions with HIV in Uganda. JAMA. 2004;292:2614-21.

19. Farsani TT, Kore S, Nadole P, Ramam M, Thiemans S, Leslie K, et al. Etiology and risk factors associated with a pruritic papular eruption in people living with HIV in India. J. Int. AIDS Soc. 2013;16:25-6.

20. Gyar SD, Reuben CR, Haruna MS. Study on the Distribution of HIV/AIDS Infections among Age Group Attending General Hospital Toto, Central Nigeria. Int J Microbiol Immunol Res. 2014;3:38-42.

21. Olajubu FA, Osinupebi OA, Deji-Agboola M, Jagun EO. Seroprevalence of HIV Among Blood Donors, Antenetal women and other patients in a Tertiary Hospital in Nigeria. Braz J Inf Dis. 2009;13:280-3.

22. Egube BA, Ofili AN, Isara AR, Onakewhor JU. Neonatal jaundice and its management: Knowledge, attitude and practice among expectant mothers attending antenatal clinic at University of Benin Teaching Hospital, Benin City. Niger J Clin Pract. 2013;16:188-94.

23. Lakshmi SJ, Rao GR, Ramalakshmi, Satyasree, Rao KA, Prasad PG, Kumar YH. Pruritic papular eruptions of HIV: a clinicopathologic and therapeutic study. Indian J Dermatol Venereol Leprol. 2008;74:501-3.

24. Castelnuovo B, Byakwaga H, Menten J. Can response of a pruritic papular eruption to antiretroviral therapy be used as a clinical parameter to monitor virological outcome? AIDS. 2008;22:269-73.

25. Liautaud B, Pape JW, DeHovitz JA, Thomas F, LaRoche AC, Verdier RI, et al. Pruritic skin lesions: A common initial presentation of acquired immunodeficiency syndrome. Arch Dermatol. 1989;125:629-32

26. Fischer BK, Warner LC. Cutaneous manifestations of the acquired immunodeficiency syndrome. Intl J Dermatol. 1987;26:615-30.

27. Chua SL, Amerson EH, Leslies KS, McCalmount TH, Leboit PE, Martin JN, et al. Factors associated with pruritic papular eruption of human immunodeficiency virus infection in the antiretroviral therapy era. Br J Dermatol. 2014;170:832-9.

28. Jayakar T, Selva PSK, Manoharan D, Ashok KN, Cynthia S, Ashwak A. Papular Urticaria-An early marker of atopic march. Sudanese J Dermatol. 2010;8:2-3.

Copyright by Obioma Ekpe, et al. This is an open-access article distributed under the terms of the Creative Commons Attribution License, which permits unrestricted use, distribution, and reproduction in any medium, provided the original author and source are credited. Source of Support: Nil, Conflict of Interest: None declared. 